University of Wollongong

Research Online

Faculty of Business - Papers (Archive)

Faculty of Business and Law

$1-1-2019$

Do tourists notice social responsibility information?

Nazila Babakhani

University of Queensland

Melanie J. Randle

University of Wollongong, mrandle@uow.edu.au

Sara Dolnicar

University of Queensland, s.dolnicar@uq.edu.au

Follow this and additional works at: https://ro.uow.edu.au/buspapers

Part of the Business Commons

Research Online is the open access institutional repository for the University of Wollongong. For further information contact the UOW Library: research-pubs@uow.edu.au 


\title{
Do tourists notice social responsibility information?
}

\begin{abstract}
This empirical study explores the amount of attention tourists pay to social responsibility (environment and community) information when booking accommodation online. Visual attention is a necessary requirement for tourists to consider the social responsibility of different accommodation options when making bookings. Eye tracking methodology was used to measure the visual attention paid to social responsibility initiatives in a simulated accommodation booking webpage. Results reveal that information about social responsibility initiatives does not attract significant visual attention from tourists, especially when they are confronted with a typically large amount of information about accommodation options. Such information is therefore unlikely to affect booking decisions. Accommodation providers can actively direct tourists' attention to social responsibility initiatives by reducing the total amount of information provided.
\end{abstract}

Disciplines

Business

Publication Details

Babakhani, N., Randle, M. \& Dolnicar, S. (2019). Do tourists notice social responsibility information?. Current Issues in Tourism, Online First 1-13. 


\section{Published as:}

Babakhani, N., Randle, M. \& Dolnicar, S. (2019). Do tourists notice social responsibility information?. Current Issues in Tourism, Online First 1-13.

\section{Tourists do not pay much attention to information about environmental} sustainability and community contribution when choosing a holiday home

Nazila Babakhani ${ }^{\mathrm{a} *}$, Melanie Randle ${ }^{\mathrm{b}}$ and Sara Dolnicar ${ }^{\mathrm{a}}$

${ }^{a} U Q$ Business School, The University of Queensland, Brisbane, Australia; ${ }^{b}$ Faculty of Business, University of Wollongong, Wollongong, Australia

*Corresponding Author

Postal address: UQ Business School, The University of Queensland, Brisbane, Queensland, 4072, Australia

Email: n.babakhani@uq.edu.au

Phone: +61426231544 


\title{
Tourists do not pay much attention to information about environmental sustainability and community contribution when choosing a holiday home
}

\author{
We test the key antecedent to tourists considering environmental and community \\ initiatives when making accommodation booking decisions: visual attention. Results \\ from an eye tracking study indicate that information about environmental and \\ community initiatives does not attract significant visual attention from tourists, \\ especially when tourists are confronted with a typical amount of information available \\ to them on online accommodation booking sites. Information about environmental and \\ community initiatives is therefore unlikely to affect booking decisions.
}

Accommodation providers can actively direct tourists' attention to environmental and community initiatives by reducing the total amount of information provided.

Keywords: sustainability, environment, community, communications, attention, eye tracking

\section{Introduction}

Many accommodation providers implement environmental and community initiatives (Jones, Hillier, \& Comfort, 2014; Kirk, 1998). The reason for this may be purely altruistic. However, given businesses do not typically increase operating costs solely for the greater good (Berry \& Ladkin, 1997; Knowles, Macmillan, Palmer, Grabowski, \& Hashimoto, 1999), the more likely reason is a belief that such initiatives positively affect the public image of the accommodation provider (Le, Hollenhorst, Harris, McLaughlin, \& Shook, 2006) and, in turn, tourists’ booking decisions.

Previous studies investigating the effect of environmental and community initiatives on booking decisions have used social-psychological models such as the theory of planned behaviour (Ajzen, 1991) and value-belief-norm theory (Stern, Dietz, Abel, Guagnano, \& Kalof, 1999). These studies assume tourists see and process the information provided about such initiatives. The present study challenges this assumption. It examines whether tourists 
pay attention to information about environmental and community initiatives when evaluating alternative accommodation options online. We investigate (1) how much attention tourists pay to information about environmental and community initiatives (relative to information about other accommodation attributes), and (2) whether attention varies with the total amount of information provided about alternative accommodation options. If this is the case, we can make practical recommendations about how businesses can proactively increase the influence of their environmental and community initiatives on bookings.

The present study makes two key contributions: (2) it deconstructs assumptions about cause and effect in booking behaviour in line with hierarchy of effect models (Barry, 1987) that postulate that attention (awareness) is a necessary condition for interest, desire and finally action; and (2) it is the first to use an objective measure of attention to information about environmental and community initiatives when assessing accommodation options online. As such, it responds directly to Juvan and Dolnicar's (2016) call to use behavioural measures to avoid the inherent bias captured by self-report measures.

Findings have practical implications for public policy makers and tourism businesses genuinely interested in drawing attention to specific types of information with a view to strengthening the demand effect of the environmental and community initiatives of tourism businesses.

\section{The importance of attention}

Social-psychological models - such as the theory of planned behaviour (Ajzen, 1991) - are widely used to explain tourists’ pro-environmental (in)action (Han, Hsu, \& Sheu, 2010; Chen \& Peng, 2012; Ong \& Musa, 2011). These models assume behaviour to be a consequence of cognitive constructs. The theory of planned behaviour, for example, postulates that behavioural intention (the antecedent of actual behaviour) results from people's attitude 
toward the behaviour, social norms (beliefs about what important others think about the behaviour), and perceived control over performing the behaviour. All four constructs require cognitive processing. The same is true for other social-psychological models that postulate slightly different cognitive antecedents of behaviour (Stern, Dietz, Abel, Guagnano, \& Kalof, 1999).

For tourists to be able to account for environmental and community initiatives during the booking decisions, they need information about these initiatives (Villarino \& Font, 2015; Font \& McCabe, 2017; Wehrli et al., 2017). For this information to affect their cognitive processing, it must be seen. Attention, therefore, represents a necessary condition for anything affecting people's non-habitual behaviour, such as booking tourist accommodation. Yet, little is known about the level of attention tourists pay to information about environmental and community initiatives by tourism service providers. Most empirical studies ignore attention as a prerequisite, focusing instead on self-reported behavioural intentions such as stated willingness to stay in green hotels (Chen \& Peng, 2012; Chen \& Tung, 2014; Gustin \& Weaver, 1996; Han, 2015; Han, Hsu, \& Lee, 2009; Han et al., 2010), revisitation intention (Lee, Hsu, Han, \& Kim, 2010), and stated willingness to pay (Choi, Parsa, Sigala, \& Putrevu, 2009; Kang, Stein, Heo, \& Lee, 2012; Kasim, 2004a,b; Kim \& Han, 2010; Manaktola \& Jauhari, 2007; Musau, 2000; Watkins, 1994). Only a few studies investigate actual behaviour, such as booking (Chong \& Verma, 2013), knowledge (Karlsson \& Dolnicar, 2016), and searching for environmental information (Reiser \& Simmons, 2005). The theory of planned behaviour serves as the basis for many of these studies (Buttle \& Bok, 1996; Chen \& Peng, 2012; Chen \& Tung, 2014; Han et al., 2010; Han \& Kim, 2010; Line \& Hanks, 2016) which, not surprisingly, conclude that attitudes, social norms and perceived behavioural control affect intention to visit green hotels in future (e.g, Chen \& Peng, 2012; Chen \& Tung, 2014; Han \& Kim, 2010; Han et al., 2010; Kim \& Han, 2010). A 
few studies have also used value-belief-norm theory (Choi, Jang, \& Kandampully, 2015) or multiple theories (Han, 2015) to explain intention to stay at green hotels. Some expand existing models by adding explanatory variables, including environmental concern (Chen \& Tung, 2014); perceived effectiveness of environmental friendly efforts and environmentally conscious behaviours (Kim \& Han, 2010), service quality, satisfaction, overall image, frequency of past behaviour (Han \& Kim, 2010); trust (Choi et al., 2015) and non-green alternative attractiveness (Han, 2015).

Regardless of the key dependent variable used in those studies and the constructs postulated to affect the degree to which environmental and community initiatives affect tourists’ booking behaviour, all prior work fails to account for attention.

\section{Measuring attention with eye tracking}

Eye tracking involves recording patterns of eye movements known as scan paths. Scan paths provide spatial-temporal data of visual attention across a stimulus. Scan paths consist of fixations and saccades. Fixations are relatively stable eye movements lasting for about 200 to 300 milliseconds. Saccades are short (20-40 milliseconds) rapid eye movements between fixations during which information processing is suppressed (Rayner, 1998).

Visual attention plays a key role in the decision making process (Orquin \& Loose, 2013). Attributes with greater importance to the decision maker receive more fixations (Glöckner, 2011; Meißner, Musalem, \& Huber, 2016; Reisen, Hoffrage, \& Mast, 2008; Su, Rao, Li, Wang, \& Li, 2012; Van Raaij, 1977; Yang, Toubia, \& De Jong, 2015). Therefore, fixation time indicates information interest (Rayner, 1998) and information utility in the decision making process (Russo, 2011). Information load affects visual attention (Lavie, 1995): more information reduces the relative amount of information fixated (Lohse \& Johnson, 1996; Reutskaja, Nagel, Camerer, \& Rangel, 2011). 
Eye tracking is a valuable tool for measuring attention in tourism (Scott, Zhang, Le, \& Moyle, 2017) and hospitality (Robson \& Noone, 2014). Eye tracking has been used to investigate the effectiveness of tourism advertisements (Scott, Green, \& Fairley, 2016; Wang \& Sparks, 2014); to design tourism experiences (Li, Scott \& Walters, 2015) such as hotel pictures (Wang, Tsai \& Tang, 2018); to optimize restaurant menus (Yang, 2012), and to assess the usability of websites (Marchiori \& Cantoni, 2015; Green, Murray, \& Warner, 2011; Pan et al., 2004; Pan, Zhang, \& Smith, 2011), including accommodation websites (Hao, Tang, Yu, \& Law, 2015; Noone \& Robson, 2014; Pan, Zhang, \& Law, 2013). The number of available options and the presence of images affect online accommodation choice. Too many options overwhelm people, and images increase attention (Pan et al., 2013). Firmand user-generated content affect online accommodation choice at different stages of decision making. During consideration set formation, pictures attract more attention than text. Later, user-generated content attracts more attention (Noone \& Robson, 2014).

\section{Methodology}

\section{Sample}

We used eye tracking to study attention to different holiday home attributes when choosing accommodation online. Because we are particularly interested in attention to environmental and community initiatives, we have deliberately selected a sample of people that theoretically - have a higher than average likelihood of considering these types of attributes. This ensures a conservative research design: if we find that this sample of tourists do not pay attention to information about environmental and community initiatives, we can safely assume that attention among the general population will be even lower. For this reason, we have only allowed highly educated women over the age of 30 to participate. This group has been identified as most like to engage in green consumption (Gilg, Barr, \& Ford, 2005). The 
sample size of 31 is typical of eye tracking studies (Glöckner, 2011; Just \& Carpenter, 1980; Krajbich, Armel, \& Rangel, 2010; Lohse, 1997; Noone \& Robson, 2014; Pan et al., 2013; Rayner, Rotello, Stewart, Keir, \& Duffy, 2001; Russo \& Rosen, 1975; Shimojo, Simion, Shimojo, \& Scheier, 2003).

\section{Research design}

During purchase decisions, information overload leads to unimportant information being screened out (Bettman, Johnson, \& Payne, 1991; Bettman, Luce, \& Payne, 1998). We therefore created two levels of information load and randomly assigned participants to one of these two conditions. Fourteen participants saw two accommodation options, each with seven attributes (low information load condition, Figure A in the Supplemental Online Material). Seventeen participants saw three accommodation options; each with 27 attributes (high information load condition, Figure B in the Supplemental Online Material). The high information load condition reflects a more realistic online booking scenario. First, study participants could scan the main page. Then, by clicking on each attribute, participants could view additional information (Tables A and B in the Supplemental Online Material). The order of attribute presentation varied across respondents to avoid order effects. Both conditions contained attributes labelled “community” and "environment”.

\section{Fieldwork administration}

We recorded participants' eye movements while they selected holiday accommodation in an eye tracking laboratory. We did not inform participants that we were particularly interested in how much attention they paid to information about environmental and community initiatives. Participants answered two questions about the likely timing of their next holiday and expected travel companions. These questions helped participants form a more specific context for the accommodation choices they were about to make. Participants sat in front of a 
computer fitted with an eye tracker. The distance between participants and the eye tracker was around $60 \mathrm{~cm}$. Participants completed a nine-point calibration procedure on the eye tracker screen. Eye movements were recorded at $300 \mathrm{~Hz}$ by infrared corneal reflection using a Tobii-TX300 desktop-mounted eye tracker.

The task started after calibration. Participants read the following instructions: "Imagine that you are booking your next holiday. Below you will see two [three] holiday homes. They are: the same price, available when you want to travel, able to accommodate the number of people you will be travelling with and located close to the beach, within walking distance to shops and within driving distance of a major wine region. You will find additional information about each of the two [three] holiday homes under the picture. If you click on each of the headings you will also be able to see more details."

Participants took as much time as they needed to explore the available accommodation options, and then marked the one they would book. After the eye tracking task, participants indicated the importance of each attribute on a questionnaire. Participants also responded to the following open ended question: "Which features made you book this holiday home?” and questions about corporate social responsibility (Sen \& Bhattacharya, 2001), pro-environmental orientation (Dunlap, Van Liere, Mertig, \& Jones, 2000), and altruism (Rushton, Chrisjohn, \& Fekken, 1981).

Data collection took around 20 minutes. Participants received a \$10 gift voucher in appreciation of their participation. The university’s human research ethics committee approved fieldwork under human ethic application number 2015001769.

\section{Data analysis}

We analysed how visual attention is distributed across accommodation attributes and the impact of the amount of information on the distribution of attention across attributes. 
While participants were considering accommodation options, we measured visual attention to specific areas of the accommodation web pages. We defined non-overlapping areas of interest around each holiday accommodation attribute (e.g. "kitchen”, "internet”) with the size of $(35 \times 160$ to $35 \times 320)$ pixels for low information load attributes, and $(25 \times 125$ to $25 \times 360$ ) pixels for high information load attributes. We created 14 and 81 nonoverlapping areas of interest for each attribute on each hotel option. In line with the eye movement literature, we assume information extraction takes place during fixations and that a minimum of 60 milliseconds is needed for meaningful extraction of information (Tobii, 2003). We measured the level of attention using total fixation time (the sum of all fixations on an area of interest) across all accommodation options. The total number of clicks on each attribute served as an additional indicator of interest in the attribute.

Non-parametric Friedman's test determined whether fixation times and numbers of clicks differed significantly across attributes in both information load conditions. Non parametric Mann-Whitney tests determined whether attributes presented in both information load conditions received significantly different total fixation time and the number of clicks across two information load conditions. P-values larger than .05 are reported as not significant (n.s.).

\section{Results}

\section{Sample description}

Participants were all university staff mostly over 35 years old (75\%). Twenty-seven (87\%) participants had bachelors, postgraduate or graduate diploma degrees. Twenty-three (75\%) earned over AU\$67,000 annually, with half earning over AU\$83,000. All participants usually booked accommodation online. They typically took four short holidays and one or two long holidays per year. All participants had gone on a holiday in the past 12 months and were 
actively involved in holiday planning. All participants stated their support for corporate social responsibility initiatives. Participants had a positive pro-environmental orientation and reported altruistic behaviour more than once for all but two altruistic personality items.

\section{Relative attention to "environment" and "community" attributes}

Figure 1 shows box plots of total fixation time and number of clicks for each attribute across accommodation options for the high information load condition. The x-axis plots fixation times in seconds (Figure 1a) and number of clicks (Figure 1b). The y-axis indicates accommodation attributes. Values more than 1.5 interquartile range from the end of a box but less than three interquartile range from the end of a box are labelled as outliers (o), and values more than three interquartile range from the end of a box are labelled as extremes, denoted with an asterisk $(*)$. The diamonds indicate mean values across participants for both fixation time and number of clicks.

Please insert Figure 1 here.

Fixation time varies significantly across attributes $\left(\chi^{2}(26)=58.62, p=.00\right)$. "Internet” and "kitchen" receive the highest fixation times (Median=2.85 and 2.70 seconds, respectively). "Safety card and first aid kit" and "intercom” receive the lowest fixation times (Median=1.15 and 1.01 seconds, respectively) (Figure 1a). A step-down follow up analysis of Friedman’s test shows that only the highest ranked attributes (“internet”, “kitchen”) receive significantly more fixation time than the lowest ranked attributes ("safety card and first aid kit”, "hair dryer”, “intercom”). All other attributes receive equal fixation times. This is probably because fixation times were measured on the first page - where study participants saw all options. Most participants at least scan the complete list of attributes initially. Single 
fixation duration analysis confirms that all attributes have a short (on average, 190 milliseconds) fixation duration (less than 250 milliseconds) (Glöckner, 2011), indicating that participants only scanned the attributes (Velichkovsky, Dornhoefer, Pannasch, \& Unema, 2000).

While fixations on the main page are, to some degree, a consequence of scanning, clicking through to the next page indicates deliberate inspection of the attribute and is perhaps a better indicator of consumer interest. The range of click-throughs across all attributes is even wider $\left(\chi^{2}(26)=159.09, p=.00\right)$ with a maximum of three ("internet") and minimum of zero (Figure 1b).

Considering the median values of the attributes, "environment” and "community” did not receive high levels of attention compared to the attribute of most interest to participants (“internet”). “Community” attracted even less attention than “environment”.

\section{Attention to "environment" and "community" attributes across information load conditions}

Participants did not spend the same amount of time inspecting the holiday accommodation options across information load conditions. On average, participants took 209 seconds to make an accommodation decision under the high information load condition, and about half as long (105 seconds) under the low information load condition. However, participants under the high information load condition looked at fewer pieces of information. Participants fixated on 81 percent and 93 percent of attributes under the high and low information load conditions, respectively.

Figure 2 contains gaze plots of two typical participants in the low and high information load conditions. Each bubble is a fixation by one respondent on one particular part of the screen. The size of the bubble indicates the duration of the fixation. Lines between bubbles are saccades or jumps between fixation points. As can be seen in Figure 2, in the low 
information load condition (yellow gaze plot on the left) the participant looked at every attribute. In the high information load condition (blue gaze plot on the right) the participant skipped a number of attributes. Figure 2 illustrates the overall pattern of attention observed, confirming that more information leads to less attention paid to some attributes. In this situation less relevant attributes are more likely to be ignored, although respondents had no time limit for studying the holiday home options.

Please insert Figure 2 here.

Figure 3 compares the distribution of total fixation time across information load conditions. For low information load, fixation time was distributed more evenly, with no significant difference across attributes $\left(\chi^{2}(6)=4.46, p=.61\right)$ (blue section in Figure 3). For high information load, the fixation time of the attribute receiving the most attention was more than twice that of the attribute receiving the least attention $\left(\chi^{2}(26)=58.62, p=.00\right)$ (red section in Figure 3).

Please insert Figure 3 here.

“Community” received significantly less fixation time when presented along with a larger number of other attributes than when it was presented with fewer attributes (Median=1.52 versus 2.86 seconds, respectively: $\mathrm{U}=67.00, \mathrm{Z}=-2.07, p=.04$ ). Similarly, "safety” received significantly less fixation time under high information load (Median =1.15 seconds) compared to low information load (Median $=2.18$ seconds): $U=63.50, Z=-2.20$, $p=.03$. Both "environment” and "community” received significantly fewer clicks when part of a larger number of attributes (Mann-Whitney environment: $\mathrm{U}=70.50, \mathrm{Z}=-2.04, p=.04$; Mann- 
Whitney community: $\mathrm{U}=58, \mathrm{Z}=-2.62, p=.01$ ). This indicates that - among the seven attributes presented in both information load conditions - the attributes "environment”, “community” and "safety" are least important. For the remaining attributes present in both conditions (“internet”, "access to the property/check in and doorman”, "heating and cooling/heating and aircon”, "washing and laundry facilities/washer and dryer”) the distribution of attention is not significantly different across two information load conditions, suggesting they are more relevant for decision making.

Click-through data supports the findings from fixation data: more information leads to a higher level of differentiation $\left(\chi^{2}(26)=159.09, p=.00\right)$ compared to the low information load condition $\left(\chi^{2}(6)=6.82, p=.34\right)$. Therefore, participants were more selective about what information they pay attention to under the high information load condition.

\section{Self-report measures}

Supporting findings from the eye tracking analysis, the range in self-reported importance of attributes is greater when participants are presented with more information (a range of 6-71\% versus 42-73\%). Under the high information load, “internet” and "kitchen” are reported to be most important (average 70\%). “Intercom” and "wheelchair accessibility” are the least important (average 9\% and 6\%, respectively). "Environment” and "community” are not among the most important attributes.

The attributes “environment” and “community”, along with other attributes (such as washing facilities, picture, view, etc.), were mentioned by five out of 14 respondents in the low information load condition. However, no participants in the high information load condition mentioned "environment” and/or "community" attributes in response to the open ended question. 


\section{Conclusions, limitations and future work}

This study investigated how much attention tourists pay to information about environmental and community initiatives when comparing holiday accommodation options online. Attention is a key prerequisite for information to be processed and affects the cognitive constructs postulated in social-psychological models to cause behaviour.

Results of an eye tracking study indicate that tourists pay relatively little attention to the environmental and community initiatives of accommodation providers. Community initiatives rank $21^{\text {st }}$ out of 27 attributes in terms of attention. Community and environmental initiatives were also less likely to be clicked on to obtain more information.

These findings contradict previous studies concluding that environmentally conscious tourists look for information about environmental and community initiatives when booking holiday (Goodwin \& Francis, 2003; Miller, 2003; Tierney, Hunt, \& Latkova, 2011). We find that - even among a group of middle-aged highly educated women (known to be most likely

to make environmentally friendly consumer choices anyway) - functional attributes of tourist accommodations receive more visual attention and are likely to outweigh any effect of environmental and community initiatives in the decision making process. These findings align with conclusions drawn from an aggregate level booking comparison of eco certified and non-certified hotels (Chong \& Verma, 2013).

As a consequence, cognitive constructs postulated to be antecedents of green hotel choice (e.g. Chen \& Peng, 2012; Chen \& Tung; Choi et al., 2015; Han, 2015; Han et al., 2009; 2010; Han \& Kim, 2010) cannot generally be assumed to affect booking behaviour. Cognitive processes, like changes or activation of beliefs, are only possible if the person making the booking decision pays attention to the stimulus. One reason for environmental initiatives not affecting demand for tourism products is lack of attention, a factor rarely discussed or accounted for in previous studies. 
Results also show that reducing the amount of information provided leads to attention being distributed more evenly across all attributes. More information, which is more reflective of typical online booking websites, negatively affects attention. People are forced to be more selective (Bettman et al., 1998) and attributes considered less relevant to the decision suffer most. In this study, information about community and environmental initiatives was filtered out. This result is consistent with prior findings that displaying a relatively small number of accommodation options is more effective in capturing guest attention than showing many options (Pan et al., 2013). In a sustainable tourism context, information overload leads to environmental and community-related attributes being filtered out and, consequently, reducing the ability of such information to impact choice. Persuading tourists to buy responsible tourism products, such as selecting green hotels, does not necessarily mean providing more sustainability related information to them (Miller et al., 2010). The lack of attention to the environment and community information revealed in this study confirms that tourists do not make rational and deliberate decisions (Araña \& León, 2016). Consequently, it is important to investigate how to communicate sustainable product attributes to tourists in order to produce more sustainable outcomes (Wehrli et al., 2017; Millar \& Baloglu, 2011).

Findings have practical value for the communication strategies of tourist accommodation providers. Knowing which information tourists pay attention to helps providers include only relevant information on websites targeting specific segments (Dolnicar, 2004). If providers wish to draw tourists’ attention to their environment and community initiatives, they should provide fewer pieces of information and avoid overloading websites with voluminous data.

The present study has a number of limitations. It uses eye tracking as an exploratory tool to offer insights about the way tourists notice and process information while booking 
accommodation online. Eye movement data determines what a person looks at but not why certain information is acquired and processed (Russo, 1978). Tourists may pay relatively little attention to environment and community attributes when booking accommodation because they are genuinely of average importance. Alternatively, there may be a niche segment of the population that cares deeply about environmental and community initiatives of accommodation providers, thus pushing up average fixation times for these attributes across the entire sample. This hypothesis could be tested in future research with larger sample sizes that enable segmentation analysis and comparison between population subgroups. If such a segment does exist, it would be suitable for targeting with environmental and communityrelated marketing messages in order to maximize the investment in such initiatives. In addition, environment and community-related attributes may differentiate accommodation alternatives in situations where the options are similar in all other respects. This could be also the topic of future research. 


\section{References}

Araña, J. E., \& León, C. J. (2016). Are tourists animal spirits? Evidence from a field experiment exploring the use of nonmarket based interventions advocating sustainable tourism. Journal of Sustainable Tourism, 24(3), 430-445.

Alam, M. S., \& Paramati, S. R. (2017). The dynamic role of tourism investment on tourism development and $\mathrm{CO}_{2}$ emissions. Annals of Tourism Research, 66, 213-215.

Ajzen, I. (1991). The theory of planned behaviour. Organizational Behaviour and Human Decision Processes, 50, 179-211.

Barry, T.E. (1987).The development of the hierarchy of effects: An historical perspective, Current Issues and Research in Advertising, 10(1-2), 251-295.

Bettman, J. R., Johnson, E., \& Payne, J. (1991). Consumer decision making. In T. R. H. Kassarjian (Eds.), Handbook of consumer behaviour (pp. 50-79). Englewood Cliffs, NJ: Prentice-Hall, Inc.

Bettman, J. R., Luce, M. F., \& Payne, J. W. (1998). Constructive consumer choice processes. Journal of Consumer Research, 25(3), 187-217.

Berry, S., \& Ladkin, A. (1997). Sustainable tourism: A regional perspective. Tourism Management, 18(7), 433-440.

Buttle, F., \& Bok, B. (1996). Hotel marketing strategy and the theory of reasoned action. International Journal of Contemporary Hospitality Management, 8(3), 5-10.

Chen, A., \& Peng, N. (2012). Green hotel knowledge and tourists' staying behaviour. Annals of Tourism Research, 39(4), 2211-2216.

Chen, A. \& Peng, N. (2014). Recommending green hotels to travel agencies' customers. Annals of Tourism Research, 48, 284-289.

Chen, M. F., \& Tung, P. J. (2014). Developing an extended theory of planned behaviour model to predict consumers' intention to visit green hotels. International Journal of Hospitality Management, 36, 221-230.

Choi, G., Parsa, H. G., Sigala, M., \& Putrevu, S. (2009). Consumers' environmental concerns and behaviours in the lodging industry: A comparison between Greece and the United States. Journal of Quality Assurance in Hospitality \& Tourism, 10(2), 93-112.

Choi, H., Jang, J., \& Kandampully, J. (2015). Application of the extended VBN theory to understand consumers' decisions about green hotels. International Journal of Hospitality Management, 51, 87-95.

Chong, H., \& Verma, R. (2013). Hotel sustainability: Financial analysis shines a cautious green light. Cornell Hospitality Report, 14(11), 6-21.

Dolnicar, S. (2004). Profiling the one- and two-star hotel guest for targeted segmentation action: A descriptive investigation of risk perceptions, expectations, disappointments and information processing tendencies, In G.I. Crouch et al. (Eds.), Consumer psychology of tourism, hospitality, and leisure, CAB International, New York, 3, 1120.

Dunlap, R., Van Liere, K., Mertig, A., \& Jones, R. (2000). Measuring endorsement of the new ecological paradigm: A revised NEP scale. The Journal of Social Issues, 56(3), 425-442.

Farmaki, A., \& Farmakis, P. (2018). A stakeholder approach to CSR in hotels. Annals of Tourism Research, 68, 58-60.

Font, X., \& McCabe, S. (2017). Sustainability and marketing in tourism: Its contexts, paradoxes, approaches, challenges and potential. Journal of Sustainable Tourism, 25(7), 869-883.

Gilg, A., Barr, S., \& Ford, N. (2005). Green consumption or sustainable lifestyles? Identifying the sustainable consumer. Futures, 37(6), 481-504. 
Glöckner, A. (2011). An eye-tracking study on information processing in risky decisions evidence for compensatory strategies based on automatic processes. Journal of Behavioural Decision Making, 24(1), 71-98.

Goodwin, H., \& Francis, J. (2003). Ethical and responsible tourism: Consumer trends in the UK. Journal of Vacation Marketing, 9(3), 271-284.

Green, B., Murray, N., \& Warner, S. (2011). Understanding website useability: An eyetracking study of the Vancouver 2010 Olympic games website. International Journal of Sport Management and Marketing, 10(3), 257-271.

Gustin, M. E., \& Weaver, P. A. (1996). Are hotels prepared for the environmental consumer? Hospitality Research Journal, 20(2), 1-14.

Han, H. (2015). Travelers' pro-environmental behaviour in a green lodging context: Converging value-belief-norm theory and the theory of planned behaviour. Tourism Management, 47, 164-177.

Han, H., Hsu, L.-T., \& Lee, J.-S. (2009). Empirical investigation of the roles of attitudes toward green behaviours, overall image, gender, and age in hotel customers' ecofriendly decision- making process. International Journal of Hospitality Management, 28(4), 519-528.

Han, H., Hsu, L.-T., \& Sheu, C. (2010). Application of the Theory of Planned Behaviour to green hotel choice: Testing the effect of environmental friendly activities. Tourism Management, 31(3), 325-334.

Han, H., \& Kim, Y. (2010). An investigation of green hotel customers' decision formation: Developing an extended model of the theory of planned behaviour. International Journal of Hospitality Management, 29(4), 659-668.

Hao, J., Tang, R., Yu, Y., Li, N., \& Law, R. (2015). Visual appeal of hotel websites: An exploratory eye tracking study on Chinese generation Y. In I. Tussyadiah \& A. Inversini (Eds.), Information and communication technologies in tourism 2015 (pp. 607-620). Lugano, Switzerland: Springer International Publishing.

He, P., He, Y., \& Xu, F. (2018). Evolutionary analysis of sustainable tourism. Annals of Tourism Research, 69, 76-89.

Jones, P., Hillier, D., \& Comfort, D. (2014). Sustainability in the global hotel industry. International Journal of Contemporary Hospitality Management, 26(1), 5-17.

Just, M. A., \& Carpenter, P. A. (1980). A theory of reading: From eye fixations to comprehension. Psychological Review, 87(4), 329-354.

Juvan, E., \& Dolnicar, S. (2016). Measuring environmentally sustainable tourist behaviour. Annals of Tourism Research, 59, 30-44.

Kang, K. H., Stein, L., Heo, C. Y., \& Lee, S. (2012). Consumers’ willingness to pay for green initiatives of the hotel industry. International Journal of Hospitality Management, 31(2), 564-572.

Karlsson, L. \& Dolnicar, S. (2016) Does eco certification sell tourism services? Evidence from a quasi-experimental observation study in Iceland. Journal of Sustainable Tourism, 24(5), 694-714.

Kasim, A. (2004a). BESR in the hotel sector: A look at tourists' propensity towards environmentally and socially friendly hotel attributes in Pulau Pinang, Malaysia. International Journal of Hospitality \& Tourism Administration, 5(2), 61-61.

Kasim, A. (2004b). Socio-environmentally responsible hotel business: Do tourists to Penang Island, Malaysia Care? Journal of Hospitality \& Leisure Marketing, 11(4), 5-28.

Kim, Y., \& Han, H. (2010). Intention to pay conventional-hotel prices at a green hotel - a modification of the theory of planned behaviour. Journal of Sustainable Tourism, 18(8), 997-1014. 
Kirk, D. (1998). Attitudes to environmental management held by a group of hotel managers in Edinburgh. International Journal of Hospitality Management, 17(1), 33-47.

Knowles, T., Macmillan, S., Palmer, J., Grabowski, P. \& Hashimoto, A. (1999). The development of environmental initiatives in tourism: Responses from the London hotel sector. International Journal of Tourism Research, 1(4), 255-265.

Krajbich, I., Armel, C., \& Rangel, A. (2010). Visual fixations and the computation and comparison of value in simple choice. Nature Neuroscience, 13(10), 1292-1298.

Lavie, N. (1995). Perceptual load as a necessary condition for selective attention. Journal of Experimental Psychology: Human Perception and Performance, 21(3), 451-468.

Le, Y., Hollenhorst, S., Harris, C., McLaughlin, W., \& Shook, S. (2006). Environmental management: A study of Vietnamese hotels. Annals of Tourism Research, 33(2), 545567.

Lee, J.-S., Hsu, L.-T., Han, H., \& Kim, Y. (2010). Understanding how consumers view green hotels: How a hotel's green image can influence behavioural intentions. Journal of Sustainable Tourism, 18(7), 901-914.

Li, S., Scott, N., \& Walters, G. (2015). Current and potential methods for measuring emotion in tourism experiences: A review. Current Issues in Tourism, 18(9), 805-827.

Line, N.D., \& Hanks, L. (2016). The effects of environmental and luxury beliefs on intention to patronize green hotels: The moderating effect of destination image. Journal of Sustainable Tourism, 24(6), 904-925.

Lohse, G. L. (1997). Consumer eye movement patterns on yellow pages advertising. Journal of Advertising, 26(1), 61-73.

Lohse, G. L., \& Johnson, E. J. (1996). A comparison of two process tracing methods for choice tasks. Organizational Behaviour and Human Decision Processes, 68(1), 2843.

Manaktola, K., \& Jauhari, V. (2007). Exploring consumer attitude and behaviour towards green practices in the lodging industry in India. International Journal of Contemporary Hospitality Management, 19(5), 364-377.

Marchiori, E., \& Cantoni, L. (2015). Studying online contents navigation: A comparison between Eye-tracking technique and self-reported investigation. In I. Tussyadiah, \& A. Inversini (Eds.), Information and communication technologies in tourism 2015 (pp. 349-359). Lugano, Switzerland: Springe.

Meißner, M., Musalem, A., \& Huber, J. (2016). Eye tracking reveals processes that enable conjoint choices to become increasingly efficient with practice. Journal of Marketing Research, 53(1), 1-17.

Millar, M., \& Baloglu, S. (2011). Hotel guests’ preferences for green guest room attributes. Cornell University Quarterly, 53, 302-311.

Miller, G. A. (2003). Consumerism in sustainable tourism: A survey of UK consumers. Journal of Sustainable Tourism, 11(1), 17-39.

Musau, P. M. (2000). Sustainable tourism: A role for Kenya's hotel industry / Patrick Muindi Musau. Thesis (M.Bus.) - University of Queensland, St. Lucia, Qld.

Noone, B., \& Robson, S. K. A. (2014). Using eye tracking to obtain a deeper understanding of what drives online hotel choice. Cornell Hospitality Report, 14(18), 6-16.

Ong, T. F., \& Musa, G. (2011). An examination of recreational divers' underwater behaviour by attitude-behaviour theories. Current Issues in Tourism, 14(8), 779-795.

Orquin, J. L., \& Loose, S. M. (2013). Attention and choice: A review on eye movements in decision making. Acta Psychologica, 144(1), 190-206.

Pan, B., Zhang, L., \& Law, R. (2013). The complex matter of online hotel choice. Cornell Hospitality Quarterly, 54(1), 74-83. 
Pan, B., Hembrooke, H., Gay, G. K., Granka, L., Feusner, M., \& Newman, J. (2004). The determinants of web page viewing behavior: An eye-tracking study. Paper presented at the Proceedings of the 2004 symposium on Eye tracking research \& applications, New York.

Pan, B., Zhang, L., \& Smith, K. (2011). A mixed-method study of user behaviour and usability on an online travel agency. Information Technology \& Tourism, 13(4), 353364.

Rayner, K. (1998). Eye movements in reading and information processing: 20 years of research. Psychological Bulletin, 124(3), 372-422.

Rayner, K., Rotello, C. M., Stewart, A. J., Keir, J., \& Duffy, S. A. (2001). Integrating text and pictorial information: Eye movements when looking at print advertisements. Journal of Experimental Psychology: Applied, 7(3), 219-226.

Reisen, N., Hoffrage, U., \& Mast, F., W. (2008). Identifying decision strategies in a consumer choice situation. Judgment and Decision Making, 3(8), 641-658.

Reiser, A., \& Simmons, D. G. (2005). A quasi-experimental method for testing the effectiveness of ecolabel promotion. Journal of Sustainable Tourism, 13(6), 590-616.

Reutskaja, E., Nagel, R., Camerer, C. F., \& Rangel, A. (2011). Search dynamics in consumer choice under time pressure: An eye-tracking study. American Economic Review, 101(2), 900-926.

Robson, S., \& Noone, B. (2014). Show me what you see, tell me what you think: Using eye tracking for hospitality research. Cornell Hospitality Report, 14(17), 6-12.

Rushton, P. J., Chrisjohn, R. D., \& Fekken, C. G. (1981). The altruistic personality and the self-report altruism scale. Personality and Individual Differences, 2(4), 293-302.

Russo, J. E. (1978). Eye fixations can save the world: A critical evaluation and a comparison between eye fixations and other information processing methodologies. In H. K. Hunt (Eds.), Advances in consumer research (pp. 561-570). Ann Arbor, MI: Association for Consumer Research.

Russo, J. E. (2011). Eye fixations as a process trace. In M. Schulte-Mecklenbeck, A. Kuhberger, \& R. Ranyard (Eds.), A handbook of process tracing methods for decision research: A critical review and user's guide (pp. 43-64). New York: Psychology Press.

Russo, J. E., \& Rosen, L. D. (1975). An eye fixation analysis of multialternative choice. Memory \& Cognition, 3(3), 267-276.

Scott, N., Green, C., \& Fairley, S. (2016). Investigation of the use of eye tracking to examine tourism advertising effectiveness. Current Issues in Tourism, 19(7), 634-642.

Scott, N., Zhang, R., Le, D., \& Moyle, B. (2017). A review of eye-tracking research in tourism. Current Issues in Tourism. 1-18.

Sen, S., \& Bhattacharya, C. (2001). Does doing good always lead to doing better? Consumer reactions to corporate social responsibility. Journal of Marketing Research, 38(2), 225-243.

Shimojo, S., Simion, C., Shimojo, E., \& Scheier, C. (2003). Gaze bias both reflects and influences preference. Nature Neuroscience, 6(12), 1317-1322.

Stern, P. C., Dietz, T., Abel, T., Guagnano, G. A., \& Kalof, L. (1999). A value-belief-norm theory of support for social movements: The case of environmentalism. Research in Human Ecology, 6(2), 81-97.

Su, Y., Rao, L.-L., Li, X., Wang, Y., \& Li, S. (2012). From quality to quantity: The role of common features in consumer preference. Journal of Economic Psychology, 33(6), 1043-1058.

Tierney, P., Hunt, M., \& Latkova, P. (2011). Do travelers support green practices and sustainable development? Journal of Tourism Insights, 2(2), 1-16. 
Tobii. (2003). Tobii technology user manual. Retrieved from http://www.tobiipro.com/siteassets/tobii-pro/user-manuals/tobii-pro-tx300-eyetracker-user-manual.pdf.

Van Raaij, W. F. (1977). Consumer information processing for different information structures and formats. Advances in Consumer Research, 4(1), 176-184.

Velichkovsky, B., Dornhoefer, S., Pannasch, S., \& Unema, P. (2000). Visual fixations and level of attentional processing. In: A. Duhowski (Eds.), Proceedings of the international conference of eye tracking research and applications (ETRA) (pp.7985), Palm Beach Gardens, FL: ACM Press.

Villarino, J., \& Font, X. (2015). Sustainability marketing myopia: The lack of persuasiveness in sustainability communication. Journal of Vacation Marketing, 21(4), 326-335.

Wang, T. C., Tsai, C. L., \& Tang, T. W. (2018). Restorative quality in tourist hotel marketing pictures: Natural and built characteristics. Current Issues in Tourism, 1-7.

Wang, Y., \& Sparks, B. (2014). An eye-tracking study of tourism photo stimuli: Image characteristics and ethnicity. Journal of Travel Research, 55(5), 588-602.

Watkins, E. (1994). Do guests want green hotels? Lodging Industry, 70-72.

Wehrli, R., Priskin, J., Demarmels, S., Schaffner, D., Schwarz, J., Truniger, F., \& Stettler, J. (2017). How to communicate sustainable tourism products to customers: Results from a choice experiment. Current Issues in Tourism, 20(13), 1375-1394.

Yang, S. S. (2012). Eye movements on restaurant menus: A revisitation on gaze motion and consumer scanpaths. International Journal of Hospitality Management, 31(3), 10211029.

Yang, L., Toubia, O., \& De Jong, M. G. (2015). A bounded rationality model of information search and choice in preference measurement. Journal of Marketing Research, 52(2), 166-183.

Zhang, J., \& Zhang, Y. (2018). Carbon tax, tourism $\mathrm{CO}_{2}$ emissions and economic welfare. Annals of Tourism Research, 69, 18-30. 


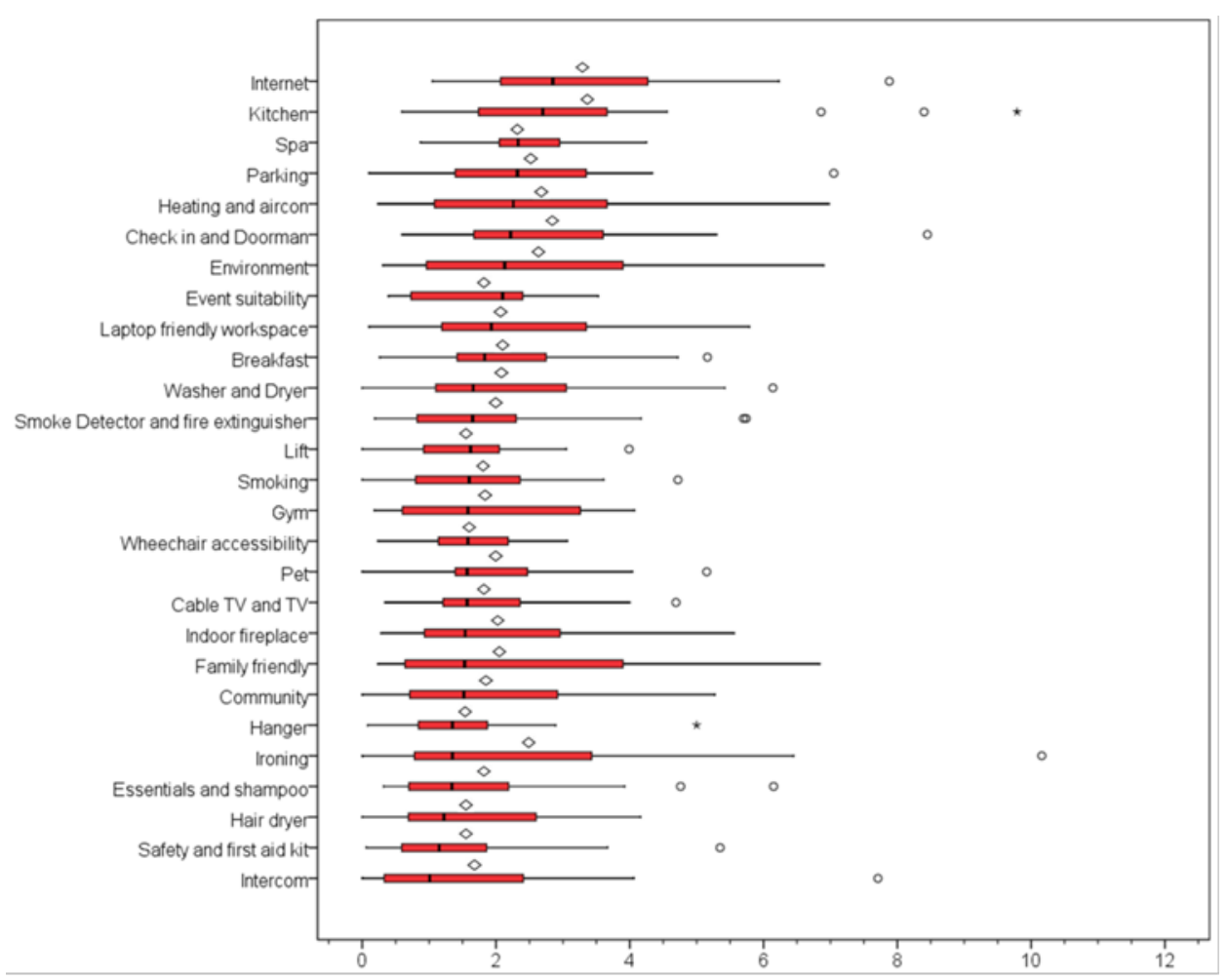

(a)

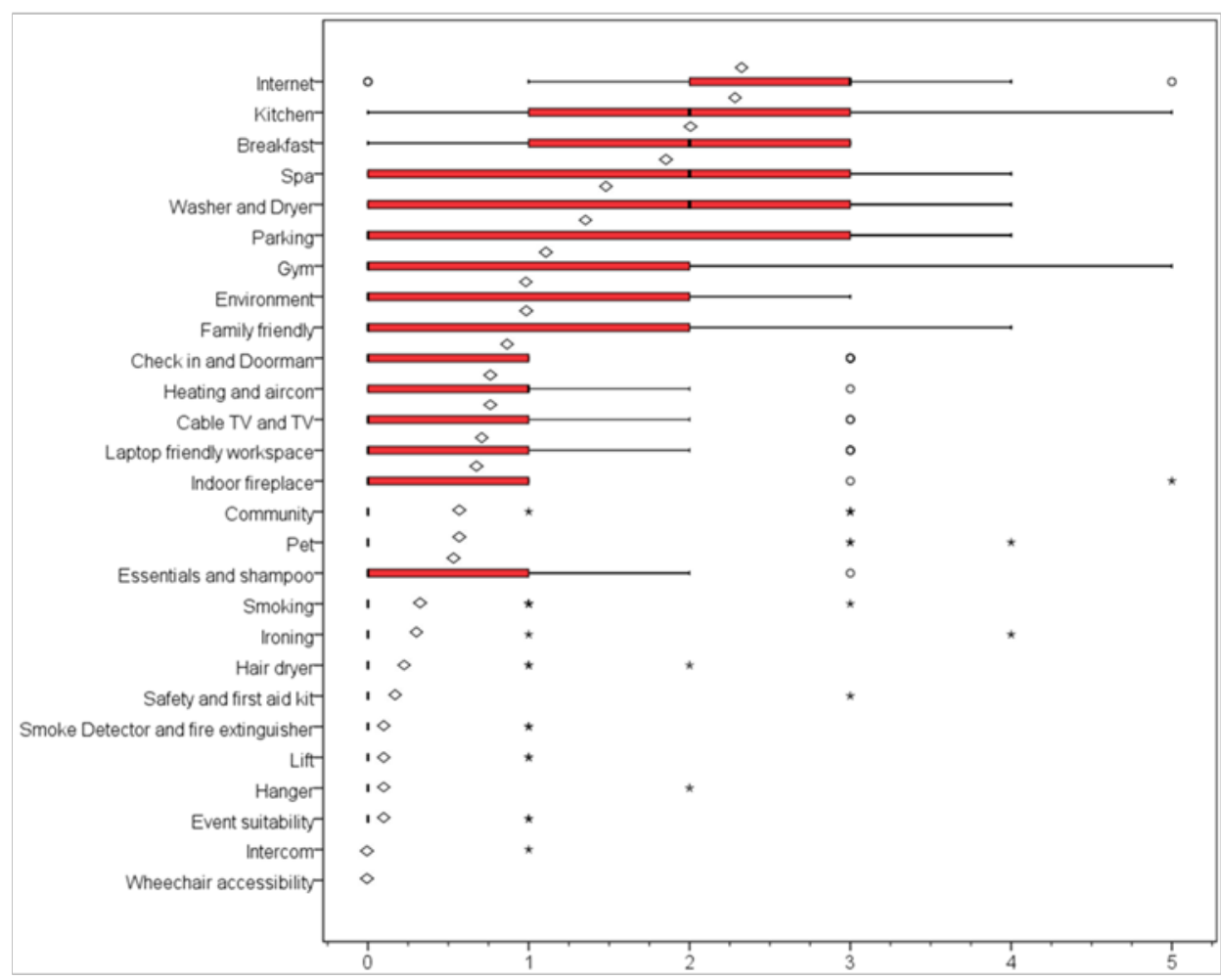

(b)

Figure 1. Fixation time (a) and number of clicks (b) for each attribute in the high information load condition. 


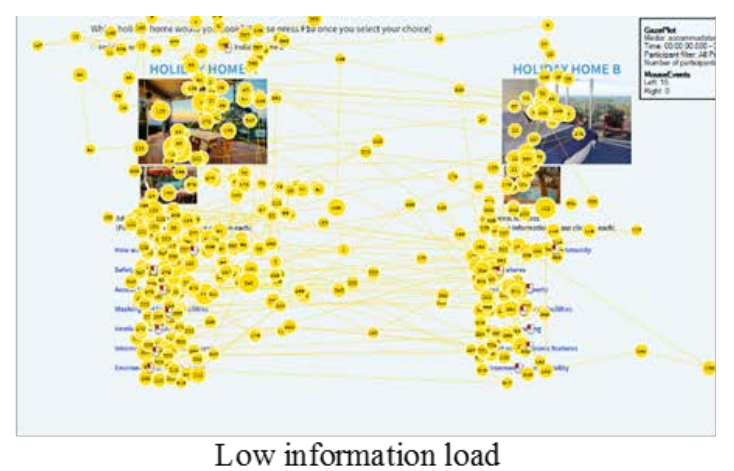

Low information load

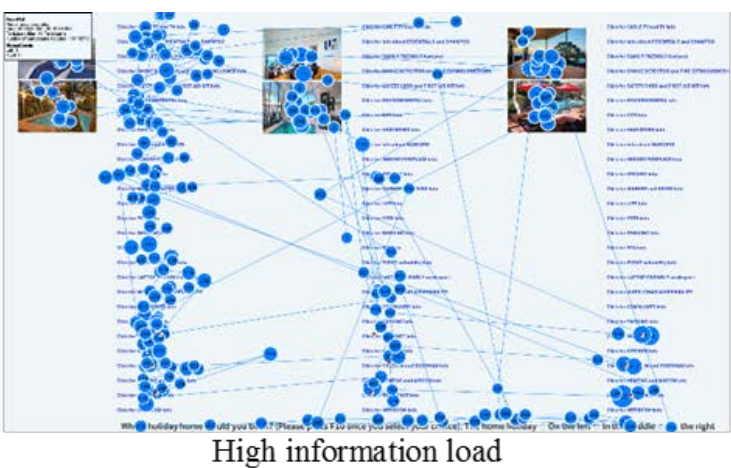

High information load

Figure 2. Gaze plots of two typical participants under the low and high information load conditions.

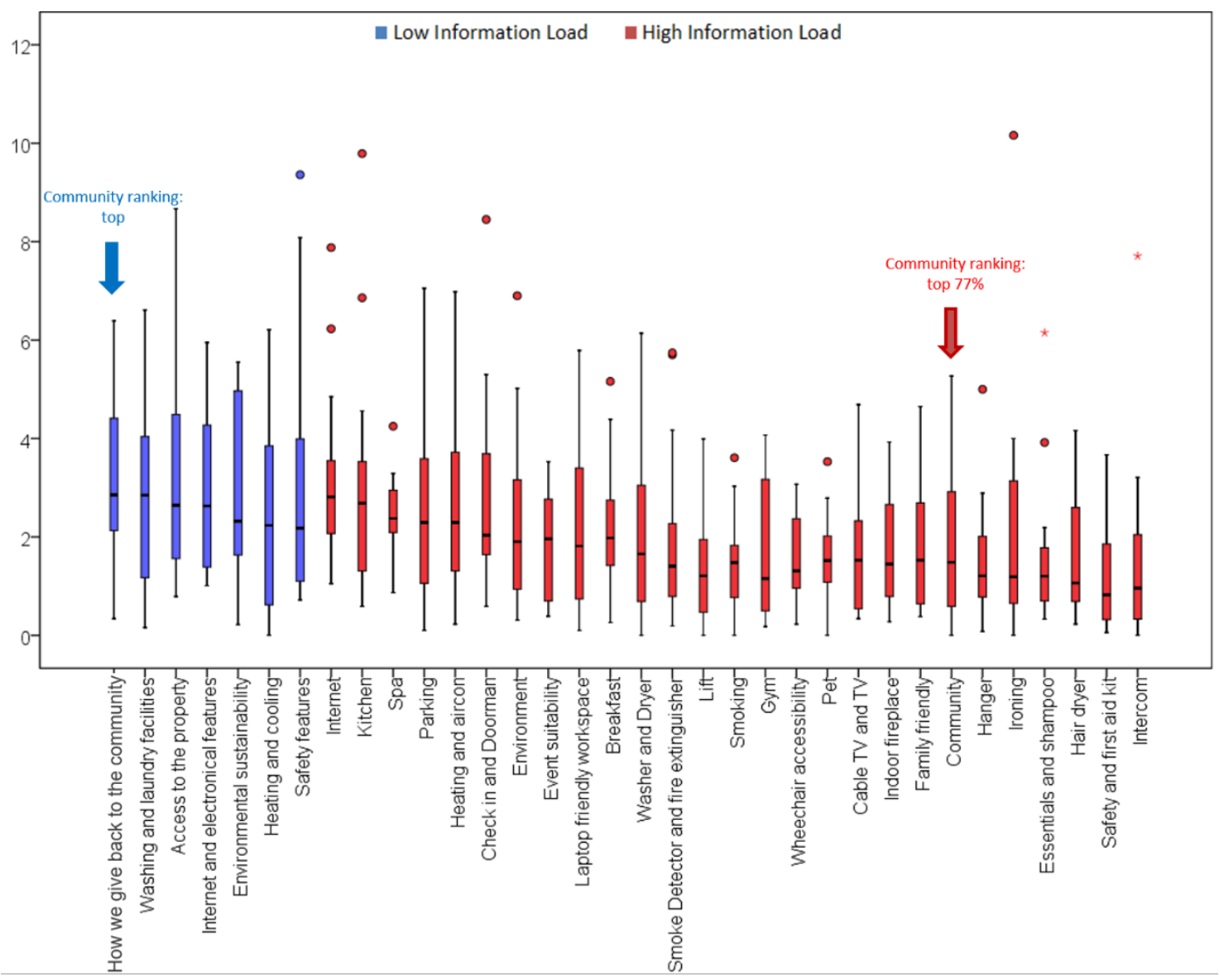

Figure 3. Fixation times under low and high information load conditions. 